\title{
Cushing's syndrome in pregnancy
}

\author{
Margarita Victoria B Holgado-Galicia, ${ }^{1}$ Jose Donato Magno, ${ }^{2}$ Czarlota Acelajado-Valdenor, ${ }^{3}$ \\ Iris Thiele Isip-Tan, ${ }^{1}$ Mary Anne Lim-Abrahan ${ }^{1}$
}

${ }^{1}$ Section of Endocrinology, Diabetes and Metabolism, Department of Medicine, University of the Philippines Manila, Philippine General Hospital, Manila, Philippines; ${ }^{2}$ Section of Cardiology, Department of Medicine, Philippine General Hospital, Manila, Philippines;

${ }^{3}$ Section of Nephrology, Department of Medicine, University of the Philippines Manila, Philippine General Hospital, Manila, Philippines

Correspondence to Dr Margarita Victoria B Holgado-Galicia, marvi.holgado@gmail.com

\section{Summary}

A 22-year-old $G_{1} P_{0}$ was admitted at 26 weeks gestation for preeclampsia, hyperglycaemia and cushingoid features. Elevated 24-h urine free cortisol (UFC) and suppressed plasma adrenocorticotrophic hormone (ACTH) suggested ACTH-independent Cushing's syndrome. Ultrasound showed left adrenal mass. She delivered preterm at 28 weeks due to severe preeclampsia and fetal distress. The infant expired after 4 days. Blood pressure was controlled after delivery and the patient was discharged on ketoconazole. Adrenalectomy was planned postpartum; however, she withdrew consent and was lost to follow-up.

A 33-year-old $G_{1} P_{1}$ presented with gestational diabetes. Pregnancy was complicated by premature delivery at 31 weeks for fetal distress. The baby improved and survived. Three months postpartum, she was evaluated for osteoporosis after sustaining a fracture from a fall. Cushingoid facies, elevated 24-h UFC, suppressed ACTH and a right adrenal mass on MRI confirmed an ACTH-independent Cushing's syndrome. She underwent adrenalectomy and improved.

\section{BACKGROUND}

Cushing's syndrome in pregnancy poses a diagnostic challenge to physicians not only because of its rare occurrence but also due to overlapping clinical features with preeclampsia and gestational diabetes. It is associated with severe maternal and fetal complications, such as spontaneous abortion, perinatal death, prematurity, maternal hypertension, diabetes, fractures and opportunistic infections. Hence, a high degree of clinical suspicion is required for early diagnosis and treatment. ${ }^{1-3}$

Pregnancy-related Cushing's syndrome is more commonly caused by adrenal adenomas than by Cushing's disease. Treatment of choice is surgery, which should ideally be done prior to the third trimester. Medical therapy may be considered as second line of treatment. Supportive therapy appears to have no role in preventing adverse outcomes to both the mother and the fetus. ${ }^{3}{ }^{4}$ We present two rare cases of Cushing's syndrome occurring during pregnancy - one detected during gestation the other postpartum. Definitive surgery was done on only one, which showed a more favourable outcome.

\section{CASE PRESENTATION}

A 22-year-old $\mathrm{G}_{1} \mathrm{P}_{0}$ was referred to our institution on her 26 th week of pregnancy for increased blood pressure (BP). A year prior to consult, she noted facial puffiness, which she attributed to weight gain. No other associated signs and symptoms were noted. She became pregnant 10 months later, during which time she started experiencing intermittent headaches and blurring of vision. Facial puffiness persisted, accompanied by increase in facial hair, abdominal striae, bipedal oedema and proximal muscle weakness. She was noted to have elevated BP (highest BP: 180 systolic) on prenatal checkup, for which she was started on methyldopa. She was then referred to an endocrinologist for evaluation.

On review of systems, pertinent to note were increased somnolence, blurring of vision, weight gain, easy fatiguability, proximal muscle weakness and easy bruisability. There was a family history of diabetes and hypertension, and the patient's sister has systemic lupus erythematosus. There was no history of malignancy in the family. Obstetric history was unremarkable.

Physical examination showed moon facies, facial acne, buffalo hump, supraclavicular fat pads and hirsutism with Ferriman and Gallwey grade 9 (figure 1). BP was elevated at 150/100, and patient was tachycardic. There were distinct violaceous striae over the abdomen and inner thighs, purpuric rashes and haematomas on both upper arms, and grade 2 pitting bipedal oedema (figures $2-4$ ). Neurologic exam was unremarkable. There were no visual field cuts on confrontation test.

She was advised admission on her 25th week of pregnancy for persistently elevated BP and thus consulted our institution.

A 33-year-old $\mathrm{G}_{1} \mathrm{P}_{1}$ (1001) presented with gradually ascending bipedal oedema on her 20th week of pregnancy. She was diagnosed with gestational diabetes based on abnormal $100 \mathrm{~g}$ oral glucose tolerance test (fetal bovine serum (FBS) $5.6 \mathrm{mmol} / \mathrm{l}, 1 \mathrm{~h} 17.2 \mathrm{mmol} / \mathrm{l}, 2 \mathrm{~h} 16.1 \mathrm{mmol} / \mathrm{l}$, $3 \mathrm{~h} 13.4 \mathrm{mmol} / 1$ (normal values (NVs) : FBS $<5.3,1 \mathrm{~h}<10$, $2 \mathrm{~h}<8.6,3 \mathrm{~h}<7.8))$ and was started on insulin therapy. At around this time, she suffered an accidental fall which caused a right-sided low back pain. MRI showed mild L5-S1 disc bulge with no evidence of focal disc herniation, spinal canal narrowing or nerve root impingement.

At 24 weeks of gestation, she noted increase in facial acne and violaceous striae on her stomach, which she attributed 


\section{BMJ Case Reports}

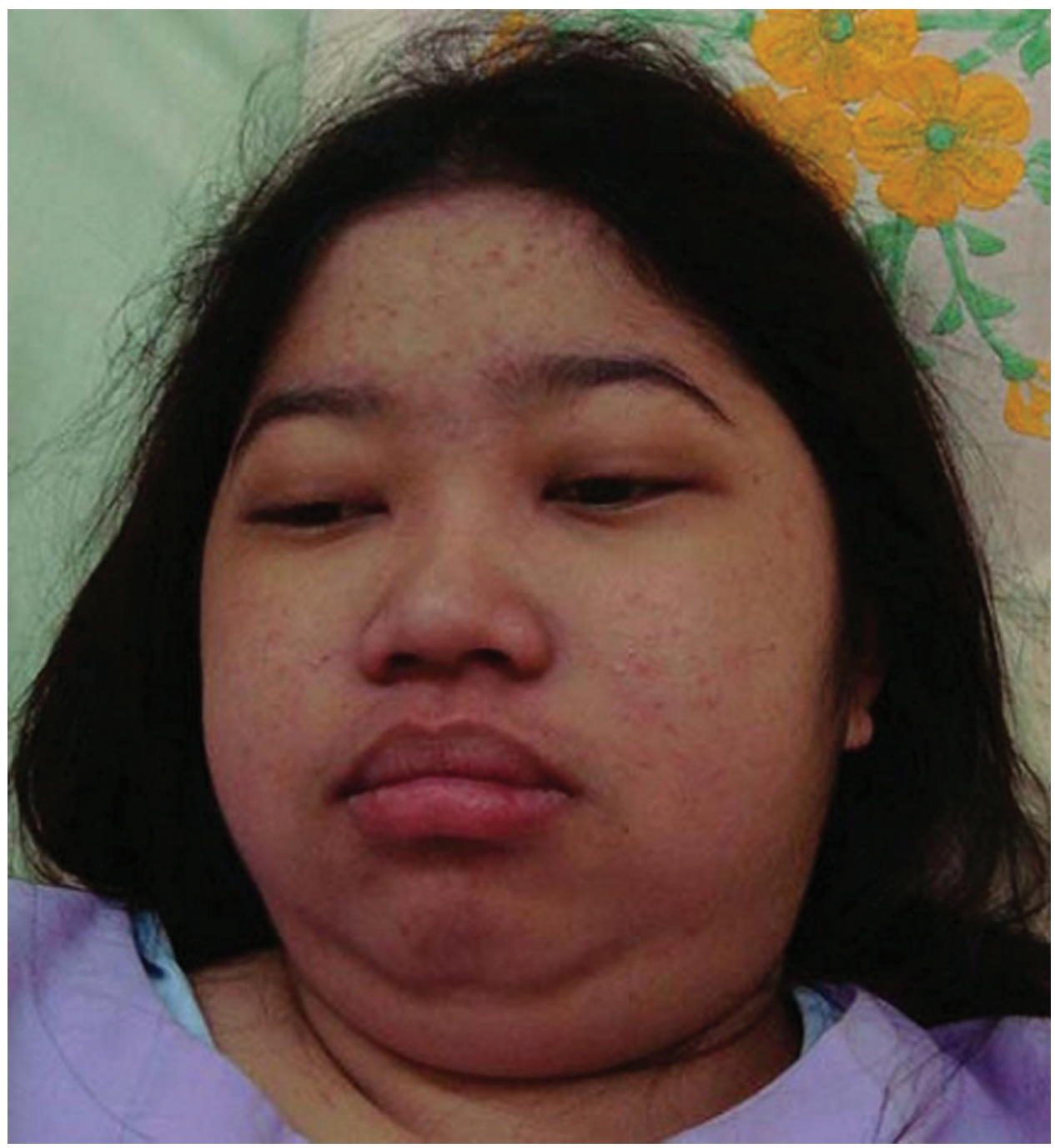

Figure 1 Moon facies.

to normal changes in pregnancy. Bipedal oedema was still present. She started to have premature uterine contractions, which initially resolved with rest and medications. However, she delivered prematurely by emergency caesarean section at 31 weeks gestation due to preterm labour and fetal distress. The baby remained in an incubator for 1 month, after which he was discharged improved.

Postpartum, the patient noted increase in facial oedema and easy bruisability. She again suffered a fall, after which she was unable to stand or move both lower extremities, prompting medical consult.

Pertinent in the physical examination were moon facies, buffalo hump, supraclavicular fat pads and violaceous abdominal striae. BP was within normal range.

Past medical and family histories were both unremarkable. The patient has a twin sister who has no similar comorbidities. The patient denies any vices or intake of steroids.

\section{INVESTIGATIONS}

Initial laboratory tests done at 17 weeks gestation showed hypokalaemia (2.3 mmol/l, NV: 3.6-5.0), proteinuria (504 mg/day, NV: 42-225), normal ultrasound of the kidneys, ureters, and urinary bladder, normal C3 and negative antinuclear antibody. A diagnosis of aldosteronoma and/or an adrenal gland tumour was considered. Further workups showed the following results:

\begin{tabular}{lll}
\hline & Results & Normal value \\
\hline 8-am serum cortisol & 1344.476 & $0-90 \mathrm{nmol} / \mathrm{l}$ \\
FT4 & 8.226 & $8.8-33 \mathrm{pmol} / \mathrm{l}$ \\
FT3 & 3.391 & $4.2-12.0 \mathrm{pmol} / \mathrm{l}$ \\
TSH & 0.949 & $0.27-3 / 75 \mu \mathrm{lU} / \mathrm{ml}$ \\
FBS & 4.12 & $3.85-6.05 \mathrm{mmol} / \mathrm{l}$ \\
Na & 145 & $136-145 \mathrm{mmol} / \mathrm{l}$ \\
Cholesterol & 5.5 & $1.3-5.2 \mathrm{mmol} / \mathrm{l}$ \\
Triglycerides & 1.79 & $0.17-1.70 \mathrm{mmol} / \mathrm{l}$ \\
HDL & 1.94 & $1.04-1.56 \mathrm{mmol} / \mathrm{l}$ \\
LDL & 3.13 & $0-2.6 \mathrm{mmol} / \mathrm{l}$ \\
\hline
\end{tabular}

Repeat laboratory tests showed thrombocytopenia (platelet count $95 \times 10^{9} / 1$ ), persistence of proteinuria and hypokalaemia. Intravenous potassium correction was done, and hydralazine was started to control BP. However, BP remained elevated. Further work-ups showed normal fasting blood glucose and glycosylated haemoglobin (4.94 mmol/1 and 4.6\%, respectively). Repeat ultrasound revealed a left suprarenal focus, likely adrenal in origin. 


\section{BMJ Case Reports}

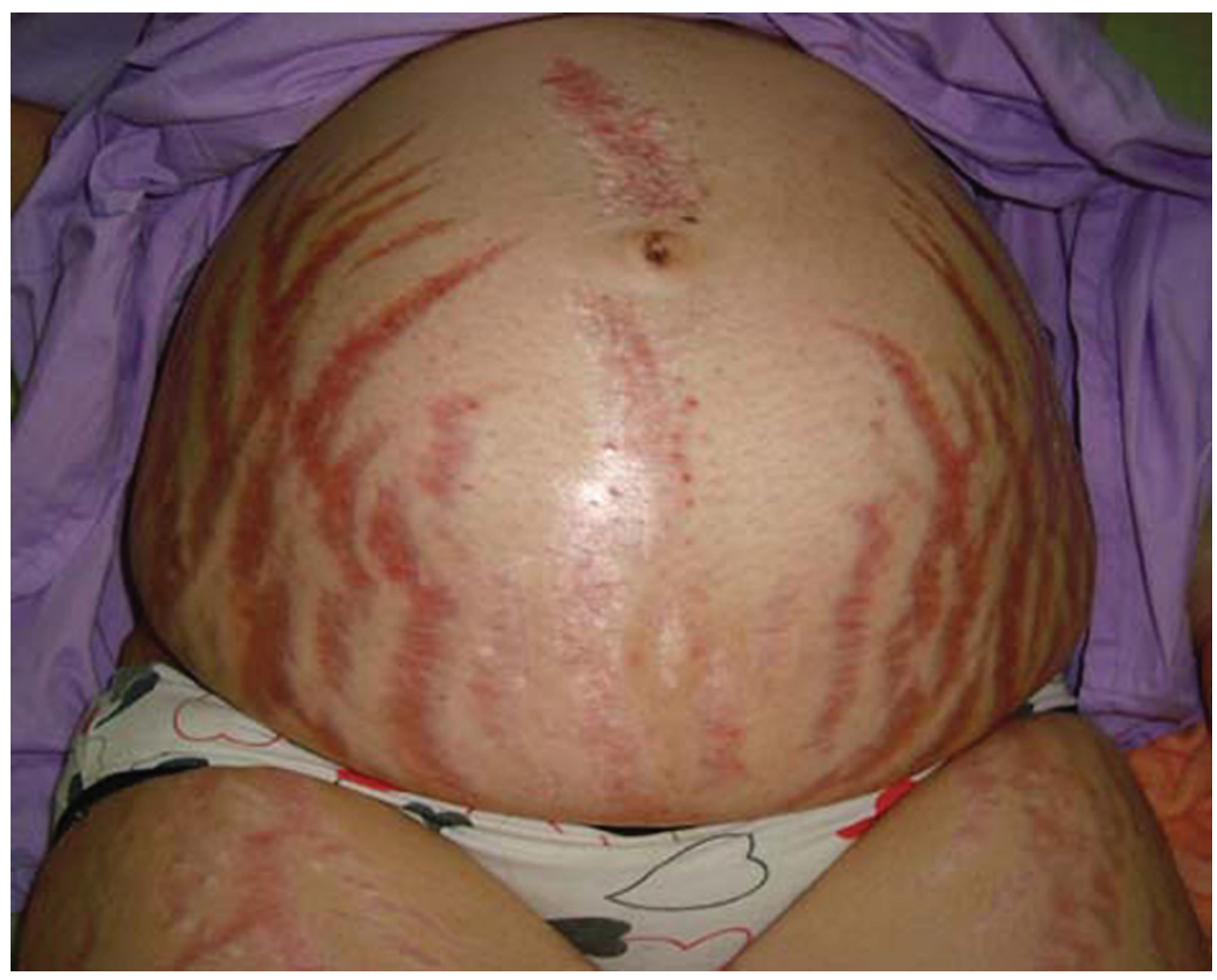

Figure 2 Abdominal striae.

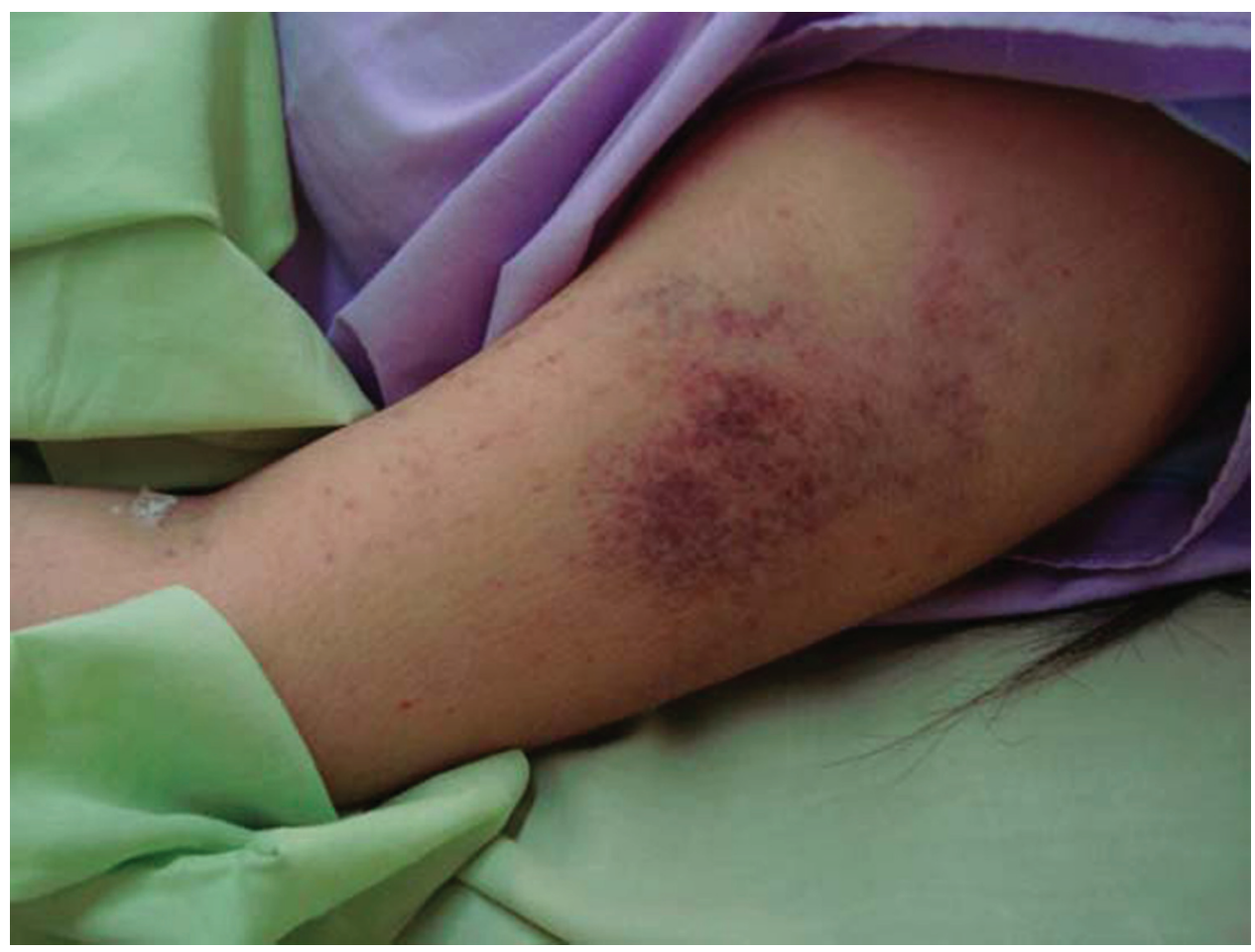

Figure 3 Easy bruisability.

She was then diagnosed to have severe pre-eclampsia and gestational diabetes mellitus, with a consideration of Cushing's syndrome.

Two-dimensional echocardiography (2D-Echo) showed eccentric left ventricular hypertrophy (LVH) with a depressed over-all systolic function and ejection fraction of $48 \%$, suggesting chronic hypertension. Funduscopic findings revealed a grade 3 hypertensive retinopathy, consistent with this impression. Work-up for Cushing's syndrome confirmed the diagnosis based on elevated 24-h urine free 


\section{BMJ Case Reports}

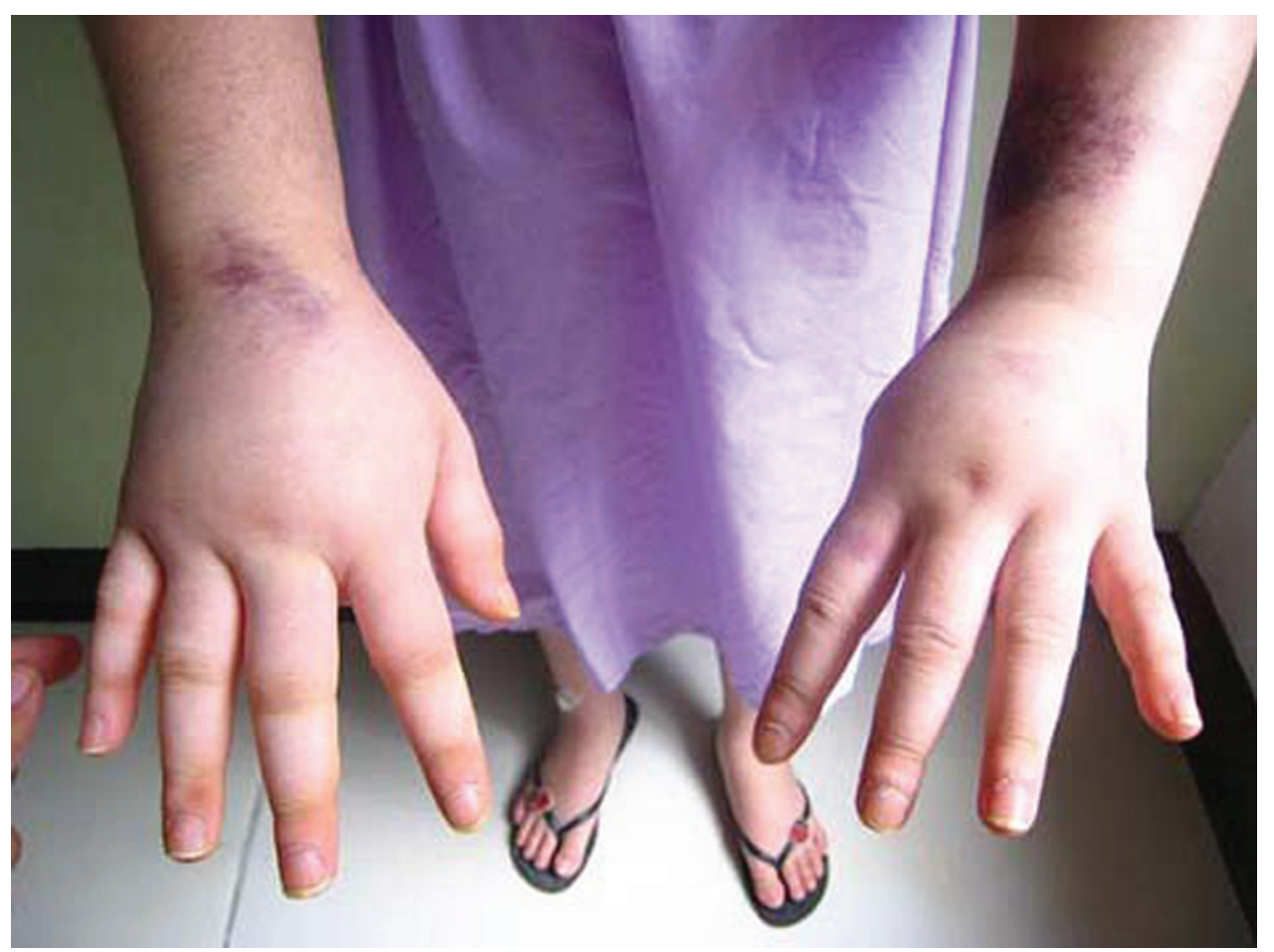

Figure 4 Extremity oedema.

cortisol (722.7 $\mu \mathrm{g} /$ day). A suppressed plasma adrenocorticotrophic hormone (ACTH) $(3.8 \mathrm{pg} / \mathrm{ml}, \mathrm{NV}:<40)$ pointed to an adrenal cause for the hypercortisolism, consistent with the finding of a left adrenal mass on ultrasound. Pheochromocytoma and hyperaldosteronism were ruled out based on normal urine metanephrine $(1.1 \mathrm{mg} /$ day $)$ and decreased plasma rennin $(0.04 \mathrm{ng} / \mathrm{ml} / \mathrm{h}, \mathrm{NV}: 0.5-1.9)$ and aldosterone $(0.14 \mathrm{ng} / \mathrm{ml}, \mathrm{NV}$ : 1.73-37.22).

Lumbosacral MRI showed compression fracture deformities on L2 and L5 vertebral bodies, likely secondary to osteoporotic fractures. Bone densitometry done showed osteoporosis. Normal vitamin D levels (51.9 nmol/l, NV: 47.7-144) and negative Bence Jones protein in urine ruled out vitamin D deficiency and multiple myeloma, respectively, as cause of the osteoporosis.

Cushing's syndrome was suspected due to typical cushingoid facies as well as the presence osteoporosis in a young female. Early morning serum cortisol was normal $(23.4 \mu \mathrm{g} / \mathrm{dl})$; however, afternoon cortisol was elevated $(23.6 \mu \mathrm{g} / \mathrm{dl})$, suggesting the loss of diurnal pattern of cortisol secretion. The diagnosis was confirmed based on an elevated 24 -h UFC (441 $\mathrm{\mu g} /$ day) with a suppressed plasma ACTH $(<5.00 \mathrm{pg} / \mathrm{ml})$, pointing to an adrenal source of the hypercortisolism. Upper abdominal and adrenal MRI showed a $3.0 \mathrm{~cm}$ solid mass on the right adrenal gland and a $1.8 \mathrm{~cm}$ nodule on the pancreatic tail. A cortisol-secreting adrenal adenoma was considered.

\section{DIFFERENTIAL DIAGNOSIS}

Differentials for the diagnosis of Cushing's syndrome included gestational diabetes, chronic hypertension and pre-eclampsia, all of which were present in the cases presented, making the diagnosis of Cushing's syndrome challenging. Differential diagnoses for the adrenal mass were a cortisol- and/or aldosterone-producing adrenocortical adenoma, malignancy and pheochromocytoma.

\section{TREATMENT}

Preprandial and 1-h postprandial hyperglycaemia were controlled with a fixed-dose regimen of isophane and regular insulin. BP, however, was persistently elevated (systolic BP 130-150 mm Hg, diastolic BP 100-110 mm Hg) despite maximal antihypertensives (hydralazine, methyldopa and nifedipine). The patient underwent emergency caesarean section for preterm labour and fetal distress at 28 2/7 weeks of gestation. The baby expired after 4 days. Adrenalectomy for the left adrenal mass was planned postpartum.

Postpartum, the patient developed transient psychosis, characterised by confusion and inappropriate response, which resolved spontaneously. BP and blood sugar levels gradually decreased, which lessened the antihypertensive and insulin requirements. Adrenal CT scan was done which revealed a $3.64 \times 3.55 \times 3.64 \mathrm{~cm}$ left adrenal mass. The patient was seen by urology service for evaluation, and laparoscopic adrenalectomy was scheduled after a month. The patient was discharged improved 2 weeks postpartum and was maintained on telmisartan, amlodipine, metoprolol, spironolactone, calcium carbonate, insulin glargine and insulin glulisine. Ketoconazole was started upon discharge.

Right adrenalectomy and distal pancreatectomy for the adrenal mass and pancreatic nodule, respectively, was done 6 months postpartum. A $3 \times 4 \mathrm{~cm}$ well-circumscribed mass was removed from the adrenal gland, which on frozen section revealed to be an adrenal adenoma. A $2 \times 2 \mathrm{~cm}$ firm, well-circumscribed mass was removed from the tail of the pancreas, which was a benign epithelial tumour on frozen section. Final histopathology showed a benign true 
cyst. She was given hydrocortisone peri-operatively and was started on prednisone immediately after surgery.

\section{OUTCOME AND FOLLOW-UP}

On follow-up a month after discharge, ketoconazole was discontinued due to note of increase in alanine transaminases (ALT $105 \mathrm{U} / 1$ from $64 \mathrm{U} / 1, \mathrm{NV}$ : 9-72). A repeat 2D-Echo showed normal left ventricular dimension with adequate systolic function. Ejection fraction was normal at $64 \%$. Repeat UFC was still elevated, $992.2 \mu \mathrm{g} /$ day. There was no increase in the size of previously noted adrenal mass on repeat adrenal CT scan. Blood sugar levels were controlled. The patient was then cleared for laparoscopic adrenalectomy.

In the interim, the patient discontinued her medications at home and upon admission for surgery developed markedly increased BP, hypokalaemia, transient psychosis and acute pulmonary oedema from left ventricular dysfunction. Surgery was deferred to optimise the patient's condition; however, the family retracted consent and decided to bring the patient home. They were then lost to follow-up.

The patient improved after adrenalectomy, with note of gradual resolution of Cushingoid facies. Gestational diabetes resolved postpartum. Repeat serum cortisol 2 days postoperatively was normal (252.50 $\mathrm{mol} / 1, \mathrm{NV}$ : 171-536). She was started on calcium supplements and prednisone postoperatively. Serum cortisol remained normal on succeeding follow-ups, and prednisone was gradually tapered and subsequently discontinued 6 months after surgery. Latest serum cortisol done a year after her operation was normal (10.6 $\mu \mathrm{g} / \mathrm{dl}, \mathrm{NV}: 5-25)$, and the patient shows no clinical signs or symptoms of hypocortisolism.

\section{DISCUSSION}

Pregnancy significantly alters the maternal hypothalamicpituitary-adrenal (HPA) axis. There is increased placental production of estrogen, which stimulates hepatic production of corticosteroid-binding globulin (CBG). Cortisol production is then stimulated, leading to an increase in circulating levels of bound cortisol. Free cortisol concentration transiently decreases as CBG increases, reducing negative feedback and increasing ACTH, which results in increased cortisol production in order to maintain a normal free cortisol level. However, both total and free plasma cortisol increase during pregnancy, with plasma cortisol noted to be two to three times elevated compared with non-pregnant women. Salivary cortisol, another measure of plasma free cortisol, is elevated by more than twofold, and 24-h UFC is also increased by at least $180 \%$. Possible explanations for these elevations include an autonomous source of ACTH and corticotrophin-releasing hormone (CRH) from the placenta, pituitary desensitisation which alters the set point to the negative feedback mechanism for ACTH and a refractory state to cortisol action due to antiglucocorticoid effects of elevated progesterone during pregnancy. ${ }^{3} 4$ Despite elevated levels, normal circadian rhythm of cortisol is preserved, although it may be partly blunted. ${ }^{3}$

The occurrence of pregnancy associated with Cushing's syndrome is rare because the state of hypercortisolism and hyperandrogenism suppress gonadotropin secretion and impair both ovarian and endometrial functions. When present, they are more commonly caused by autonomous cortisol hypersecretion from adrenal adenomas than by excessive ACTH secretion from a corticotrope or an ectopic tumour. This is in contrast to non-pregnant adults, wherein $~ 60 \%$ of Cushing's syndrome is caused by a pituitary-dependent adrenal hyperplasia. ${ }^{5} 6$

Hunt and $\mathrm{McC}$ Conahey ${ }^{7}$ first described this condition in 1953 when they reported 18 pregnancies among 11 patients with associated diseases of the adrenal glands. Of these, seven pregnancies occurred in four women with active, untreated Cushing's syndrome. ${ }^{7}$ Since then, at least 140 pregnancies have been reported in 126 subjects in individual case reports and case series. ${ }^{1-12}$ In the Philippines, no documented case of Cushing's syndrome associated with pregnancy has yet been reported in literature. A similar case reported in 1999 by Ricero ${ }^{13}$ of a 37-year-old woman diagnosed with adrenocortical carcinoma who developed metastasis during pregnancy had no confirmation of Cushing's syndrome by appropriate laboratory work-ups. ${ }^{13}$

\section{CLINICAL PRESENTATION}

The presenting features of Cushing's syndrome are similar among the pregnant and non-pregnant women, such as weight gain, hypertension, easy bruisability and hirsutism. Oftentimes, these changes are ascribed to pregnancy or to complications of pregnancy, such as preeclampsia and gestational diabetes, causing a delay in the diagnosis of Cushing's syndrome. ${ }^{4}$

In our first case, the patient presented with typical features of Cushing's syndrome as well as concomitant preeclampsia and gestational diabetes. However, the presence of a pre-existing hypertension could not be ruled out due to findings suggestive of chronicity, such as hypertensive retinopathy and eccentric $\mathrm{LVH}$.

\section{Cardiovascular changes}

Cortisol has been recognised to exert a wide range of effects on cardiovascular regulation. ${ }^{14}$ In addition to promoting hypertension through a variety of mechanisms, it may act directly on myocardial tissue, through mineralocorticoid receptors that have been demonstrated in human cardiomyocytes. ${ }^{15}$ Cortisol may also potentiate cardiac noradrenaline and angiotensin II responsiveness or stimulate the local renin-angiotensin system. ${ }^{16-18}$ The combination of Cushing's syndrome and pregnancy poses an even greater cardiovascular burden on the patient. Pregnancy in itself is a major factor that significantly alters a person's haemodynamics. An increase in stroke volume and heart rate lead to cardiac output variability. Moreover, such an augmentation in cardiac output is likewise brought about by increased metabolic demands of both the mother and the fetus. Other physiologic consequences of pregnancy include an increase in the resting oxygen consumption of the parturient, increased hormonal levels (estrogen, prostaglandins), sodium and water retention and blood volume expansion, ultimately leading to vasodilatation and diminished systemic and pulmonary vascular resistance. Such changes commence early in pregnancy and peak during the second trimester, then plateau until delivery. Prolonged cortisol exposure, in addition to hormone circulating amount 
or $\mathrm{BP}$ increase, has been the most relevant determinant of structural and functional characteristics described in patients with Cushing's syndrome. ${ }^{19}$

The mechanisms which lead to LVH have not been fully elucidated. Various hormones play specific roles in different subsets of hypertension. ${ }^{20}$ It has been surmised that the activation of mineralocorticoid receptors in cardiac tissue might play a role in myocardial hypertrophy and cardiac remodelling. ${ }^{21}$ The resulting cardiomyopathy has also been postulated to arise from cortisol-mediated overstimulation of myocardial mineralocorticoid receptors. The excess cortisol then increases the angiotensinogen synthesis and local production within the septum of angiotensin II through the myocardial renin-angiotensin system. Additional histopathologic evidence in the form of increased cardiac fibrosis has also been noted in endomyocardial biopsies from patients with Cushing's syndrome. ${ }^{22}$

\section{Osteoporosis}

Endogenous glucocorticoid excess has been shown to lead to bone loss and osteoporotic fractures. It inhibits bone formation, increases bone resorption, impairs intestinal calcium absorption and affects the secretion of gonadotropins and growth hormone, which influence bone metabolism. Trabecular bone are mainly affected, involving the vertebra in up to $70 \%$ of cases. ${ }^{23}$ This would explain the finding of pathologic fracture in our second case.

\section{DIAGNOSIS}

Screening tests for Cushing's syndrome in non-pregnant individuals demonstrate enhanced cortisol production, deranged diurnal rhythm or blunted response of cortisol to dexamethasone suppression. In pregnancy, however, gestation alters the HPA axis such that parameters used for screening becomes difficult to interpret. Mean morning plasma cortisol levels are similar in pregnant women with and without Cushing's syndrome and thus would not be able to establish the diagnosis. The nocturnal nadir in plasma cortisol is preserved in pregnancy but is lost in Cushing's syndrome. However, no studies have yet developed a diagnostic threshold for interpretation of this test in pregnant patients. ${ }^{3}$

Lindsay and Nieman recommend the use of both UFC and midnight salivary cortisol for screening of Cushing's syndrome in pregnancy. An elevated midnight salivary cortisol and a UFC more than three times the upper limit of normal confirms the diagnosis. Plasma ACTH is then recommended and a low level should prompt imaging of the adrenals. For borderline ACTH levels, a combination of the 8-mg dexamethasone suppression test and CRH stimulation test is suggested in order to establish the presence of and distinguish between the ACTH-dependent forms of Cushing's syndrome. ${ }^{3}$

\section{TREATMENT}

Untreated Cushing's syndrome in pregnancy is associated with significant maternal and fetal morbidity and mortality. In a review done by Lindsay et al of 136 pregnancies among 122 women with Cushing's syndrome, there was $89 \%$ live births among women who received treatment compared with $76 \%$ live births in women who received none. ${ }^{2}$ The most common associated maternal complications are hypertension, diabetes or impaired glucose tolerance and pre-eclampsia. Other possible consequences include poor wound healing, osteoporosis, fracture, severe psychiatric complications, heart failure and death. The most common fetal morbidity include prematurity, intrauterine growth retardation and stillbirths. ${ }^{3}$

Lindsay and Nieman recommend surgery as treatment of choice for Cushing's syndrome in pregnancy, ideally done prior to the third trimester, with medical therapy being a second choice. Metyrapone has been used more often and is generally well tolerated, with no noted adverse effects on maternal hepatic functioning or fetal development. However, it has the potential for exacerbating hypertension and progression to pre-eclampsia. ${ }^{3}$ Ketoconazole has been most useful in the control of hypercortisolism; however, it is teratogenic and embryotoxic in animals. ${ }^{24}$ It is recommended only for those who are intolerant of metyrapone or in need of emergency medical therapy. ${ }^{3}$

\section{Learning points}

- The overlap in clinical features with pregnancy, as well as its rare occurrence, makes the diagnosis of Cushing's syndrome difficult and often leads to late detection.

- A high index of clinical suspicion for Cushing's syndrome in pregnancy is required for early intervention and prevention of maternal and fetal morbidity and mortality.

- Adrenalectomy remains to be the definitive cure for Cushing's syndrome secondary to an adrenal adenoma, with medical therapy only as second line in treatment.

\section{Competing interests None.}

Patient consent Obtained.

\section{REFERENCES}

1. Kita M, Sakalidou M, Saratzis A, et al. Cushing's syndrome in pregnancy: report of a case and review of the literature. Hormones (Athens) 2007;6:242-6.

2. Lindsay JR, Jonklaas J, Oldfield EH, et al. Cushing's syndrome during pregnancy: personal experience and review of the literature. J Clin Endocrinol Metab 2005;90:3077-83.

3. Lindsay JR, Nieman LK. The hypothalamic-pituitary-adrenal axis in pregnancy: challenges in disease detection and treatment. Endocr Rev 2005;26:775-99.

4. Vilar L, Freitas Mda C, Lima LH, et al. Cushing's syndrome in pregnancy: an overview. Arq Bras Endocrinol Metabol 2007;51:1293-302.

5. Kim HG, Lee KH, Je GH, et al. A case of Cushing s syndrome in pregnancy secondary to an adrenal cortical adenoma. J Korean Med Sci 2003:18:444-6.

6. Buescher MA, McClamrock HD, Adashi EY. Cushing syndrome in pregnancy. Obstet Gynecol 1992;79:130-7.

7. Hunt $\mathbf{A B}, \mathrm{Mc}$ Conahey WM. Pregnancy associated with diseases of the adrenal glands. Am J Obstet Gynecol 1953;66:970-87.

8. Doshi S, Bhat A, Lim KB. Cushing's syndrome in pregnancy. J Obstet Gynaecol 2003;23:568-9.

9. Oh HC, Koh JM, Kim MS, et al. A case of ACTH-producing pheochromocytoma associated with pregnancy. Endocr J 2003;50:739-44.

10. White FA. Functioning adrenal cortical carcinoma in pregnancy. South Med J 1994;87:380-3.

11. Klibanski A, Stephen AE, Greene MF, et al. Case records of the Massachusetts General Hospital. Case 36-2006. A 35-year-old pregnant woman with new hypertension. N Engl J Med 2006;355:2237-45.

12. Tejura $\mathbf{H}$, Weiner J, Gibby 0 , et al. Cushing's syndrome in pregnancy. J Obstet Gynaecol 2005;25:713-14. 


\section{BMJ Case Reports}

13. Ricero $\mathbf{C P}$. Adrenocortical carcinoma and pregnancy: a case report. Far Eastern University - Dr. Nicanor Reyes Medical Foundation. Med J 1999;5:11-22.

14. Whitworth JA, Mangos GJ, Kelly JJ. Cushing, cortisol, and cardiovascular disease. Hypertension 2000:36:912-16.

15. Lombès $\mathbf{M}$, Alfaidy $\mathrm{N}$, Eugene $\mathrm{E}$, et al. Prerequisite for cardiac aldosterone action. Mineralocorticoid receptor and 11 beta-hydroxysteroid dehydrogenase in the human heart. Circulation 1995;92:175-82.

16. Ritchie CM, Hadden DR, Hennedy L, et al. Pathogenesis of hypertension in Cushing's disease. J Hypertens Supp/ 1987:5(Suppl 5):S497-9.

17. Sudhir K, Jennings GL, Esler MD, et al. Hydrocortisone-induced hypertension in humans: pressor responsiveness and sympathetic function. Hypertension 1989:13:416-21.

18. Dzau VJ. Cardiac renin-angiotensin system. Molecular and functional aspects. Am J Med 1988:84:22-7.
19. Muiesan ML, Lupia M, Salvetti M, et al. Left ventricular structural and functional characteristics in Cushing's syndrome. J Am Coll Cardiol 2003;41:2275-9

20. Catena C, Colussi G, Lapenna R, et al. Long-term cardiac effects of adrenalectomy or mineralocorticoid antagonists in patients with primary aldosteronism. Hypertension 2007;50:911-18.

21. Schmidt BM, Schmieder RE. Aldosterone-induced cardiac damage: focus on blood pressure independent effects. Am J Hypertens 2003;16:80-6.

22. Sugihara N, Shimizu M, Shimizu K, et al. Disproportionate hypertrophy of the interventricular septum and its regression in Cushing's syndrome. Report of three cases. Intern Med 1992;31:407-13.

23. Chiodini I, Torlontano M, Carnevale V, et al. Skeletal involvement in adult patients with endogenous hypercortisolism. J Endocrinol Invest 2008;31:267-76.

24. Aron DC, Schnall AM, Sheeler LR. Cushing's syndrome and pregnancy. Am J Obstet Gynecol 1990;162:244-52.

This pdf has been created automatically from the final edited text and images.

Copyright 2011 BMJ Publishing Group. All rights reserved. For permission to reuse any of this content visit http://group.bmj.com/group/rights-licensing/permissions.

BMJ Case Report Fellows may re-use this article for personal use and teaching without any further permission.

Please cite this article as follows (you will need to access the article online to obtain the date of publication).

Holgado-Galicia MVB, Magno JD, Acelajado-Valdenor C, Isip-Tan IT, Lim-Abrahan MA. Cushing's syndrome in pregnancy. BMJ Case Reports 2011;

10.1136/bcr.01.2011.3720, date of publication

Become a Fellow of BMJ Case Reports today and you can

- Submit as many cases as you like

- Enjoy fast sympathetic peer review and rapid publication of accepted articles

- Access all the published articles

- Re-use any of the published material for personal use and teaching without further permission

For information on Institutional Fellowships contact consortiasales@bmjgroup.com

Visit casereports.bmj.com for more articles like this and to become a Fellow 